\title{
Microbiological Investigation of Water Samples from Intensive Care Unit (ICU) of Tertiary Care Hospitals of Dhaka, Bangladesh
}

\section{Shah Murshid UJ Jaman Arowan, Abdihakim Ismail Ali and Saurab Kishore Munshi* \\ Department of Microbiology, Stamford University Bangladesh, Dhaka, Bangladesh \\ *Corresponding Author: Saurab Kishore Munshi, Department of Microbiology, Stamford University Bangladesh, Dhaka, Bangladesh.}

Received: May 23, 2021

Published: June 07, 2021

(C) All rights are reserved by Saurab Kishore Munshi., et al.

\begin{abstract}
Water could be a crucial transmitter of nosocomial infections in patients who are admitted to hospitals' Intensive Care Unit (ICU). The present study was undertaken to evaluate the microbiological quality of different water samples from ICU of tertiary care hospitals for measuring their potential of causing nosocomial infections. In this regard, drinking and tap water samples were collected from the ICU of three tertiary care hospitals located in Dhaka, Bangladesh. Total viable bacteria were present in an average of 3 log $_{10}$ $\mathrm{cfu} / \mathrm{ml}$ in all the samples. Among the specific bacterial isolates, Pseudomonas spp. and Bacillus spp. were predominant and encountered in all samples. E. coli contamination was observed in almost all water samples collected of the three ICUs. Staphylococcus spp. and Klebsiella spp. were recovered in water samples from ICU-1 and ICU-2. Fecal coliforms and Vibrio spp. were alarmingly found in the tap water samples of ICU-1. A few of the isolates from the water samples of ICUs were able to form biofilm on the Congo red media that accelerate the risk. Moreover, the bacterial isolates were found to be multidrug resistant. Higher resistance was found against Cefixime, Amoxicillin, Nalidixic Acid, Cephradine and Piperacillin. Overall, The findings of the present study reveal that the tested ICU water samples could be a potential source of nosocomial infections by the drug-resistant bacteria.
\end{abstract}

Keywords: Intensive Care Unit; Nosocomial Infection; Drinking Water; Water Quality; Bacterial Pathogens; Drug Resistance

\section{Abbreviations}

ICU: Intensive Care Unit; NI: Nosocomial Infection; TVB: Total Viable Bacteria

\section{Introduction}

A hospital-acquired infection or nosocomial infection (NI) may be defined as any clinically identifiable microbiological disease that affects the patient as a consequence of his stay after $48-72$ hours of admission to a hospital [1]. Hospital-acquired infections in the Intensive Care Unit (ICU) heighten sufferings and mortality in patients [2]. Environmental pollution in the hospital and ICUs is considered to be a major source of nosocomial infections as the environment can make it easier to spread some major pathogens including Gram-negative bacilli [2-4]. The assessment of health facilities environments (air, water, surfaces), including the assessment of the risk of infection in ICU, has now become part of a good health and safety policy [5]. Although several sources cause nosocomial outbreaks in hospitals, hospital water may be the most underestimated, significant and considerable source of nosocomial pathogens [6]. 
Water is a crucial public health component and failing to provide clean water would put a heavy burden on humanity $[7,8]$. In developing countries, the primary source of microbial pathogens that cause infections is drinking water [9]. Water pollution may result from the introduction of disease-causing pathogens from the pilling of garbage, unregulated waste disposal and overuse of farming chemicals which are a common scenario in Bangladesh [8]. A lack of clean drinking water and adequate sanitation leads to several diseases such as cholera, dysentery, salmonellosis, typhoid, etc. that may result in millions of deaths per day $[8,10]$. It is estimated that there is no access to clean water for 1,1 billion in developed countries, and no sanitation for 2,4 billion people. As a result, 250 million people are exposed to waterborne diseases, leading to 10 20 million deaths annually [8].

The supply source, the holding tank, the overhead tanks, the pipelines, and inefficient purification systems will all lead to contamination of the water. The tendency of microbes to survive in hospital water tanks was first described more than 30 years ago, and multiple reports have demonstrated water as a source of nosocomial infection $[5,11]$. Complex water distribution system in healthcare facilities along with different variable physical factors may lead to the formation of biofilms and promote the growth of environmental opportunistic pathogens [12]. In the hospital, the transmission of waterborne microorganisms to patients occurs directly when showering, bathing, and drinking water or ice. Patient exposure may also result from interaction with polluted surgical equipment or clinical devices and through the hands of healthcare personnel that has been rinsed or washed with tap water [13]. Even small amounts of organisms present in water can cause infection, especially in immunocompromised patients. Due to the frequent use of antibiotics in the hospital, these organisms can potentially become antibiotic resistant and responsible for spreading resistance [5]. Therefore, hospital water needs to be free from pathogenic microorganisms.

ICU is considered to be responsible for 20 - 25\% of nosocomial infections although ICU holds $<5 \%$ of hospital beds $[1,14]$. A range of $5 \%-30 \%$ of ICU patients has encountered Nis. Recently, the elevated morbidity and mortality associated with nosocomial infections in the ICU is a critical issue [1]. Having a surveillance system to find out the risk factors can reduce Nis by many folds. Considering all the facts, this study was an attempt to determine the mi- crobiological quality of drinking and tap water samples collected from the ICU of tertiary care hospitals as a potential risk factor of nosocomial infections. Screening for the presence of drug resistant bacteria and their ability to form biofilm was also conducted.

\section{Materials and Methods}

Study area, sampling and sample processing

Drinking (filtered and supplied in jar) and tap water samples were collected from different points of the Intensive Care Unit (ICU) of three different tertiary care hospitals of Dhaka, Bangladesh of Dhaka city, Bangladesh during February and March 2020. Sampling was conducted in sterile screw-capped bottles in an aseptic manner, kept at $25^{\circ} \mathrm{C}$ in a thermal stabilizing box and transported to the laboratory immediately. The samples were prepared for the microbiological assay according to the standard protocol [15-18].

Isolation and enumeration of bacteria from the water samples

For the enumeration of total viable bacteria (TVB), $100 \mathrm{ml}$ of each sample was filtered through a $0.45 \mu \mathrm{m}$ membrane filter (Pall Corporation, Port Washington, USA) that aseptically placed onto the Nutrient agar. And plates were incubated at $37^{\circ} \mathrm{C}$ for 24 hours. Likewise, the samples were introduced onto the Membrane Fecal Coliform (MFC) agar and MacConkey agar using membrane filtration technique for the enumeration of total fecal coliform (TFC), and coliforms (especially, Escherichia coli and Klebsiella spp.), respectively [15-17]. Plates were incubated for 24 hours at $44.5^{\circ} \mathrm{C}$ and $37^{\circ} \mathrm{C}$ for fecal coliform and coliforms, correspondingly.

Bacillus spp., Staphylococcus spp. and Pseudomonas spp. were introduced onto Starch agar, Mannitol Salt Agar (MSA) and Pseudomonas agar, respectively by adding $0.1 \mathrm{ml}$ of each of the samples through spread plate technique and all the plates were then incubated at $37^{\circ} \mathrm{C}$ for 24 hours [15-23].

Ten (10) $\mathrm{ml}$ of sample was transferred into $90 \mathrm{ml}$ of Selenite Cysteine Broth (SCB) and Alkaline Peptone Water (APW) for the enrichment of Salmonella spp., Shigella spp., and vibrio spp., respectively and incubated at $37^{\circ} \mathrm{C}$ for 6 hours. After incubation, 0.1 $\mathrm{ml}$ of each corresponding suspension were spread onto SalmonellaShigella (SS) agar and Thiosulfate Citrate Bile Salt Sucrose (TCBS) agar for the isolation of Salmonella spp. Shigella spp., and Vibrio spp., respectively. Plates were incubated at $37^{\circ} \mathrm{C}$ for 24 hours for the detection of typical colonies [15-23]. 
Finally, all the isolates were biochemically examined by performing triple sugar iron test, motility indole urease test, methyl red test, Voges Proskauer test, indole utilization test and the oxidase test following standard procedures as described earlier [1523].

In vitro formation of biofilm by congo red agar assay

Congo red agar was used for the biofilm production of bacteria isolated from the tested water samples. The media plates were inoculated with the bacteria by streak plate technique and incubated for 24 to 48 hours at $37^{\circ} \mathrm{C}$. The presence of black-colored colony was indicative of biofilm formation and red-colored colony was considered negative [24].

\section{Antibiotic susceptibility test of the isolates}

The standard agar-disc-diffusion method (Kirby Bauer technique) was used to examine the antibiotic susceptibility pattern (either sensitive or resistant) of the waterborne isolates on Mueller-Hinton agar (Difco, Detroit, MI) [15,18,21-23]. The commercial antibiotic discs used in this experiment were Gentamycin (GEN, 10 $\mu \mathrm{g}$ ), Trimethoprim/sulfamethoxazole (COT, $25 \mu \mathrm{g}$ ), Levofloxacin (LE, $5 \mu \mathrm{g}$ ), Nalidixic Acid (NA, $30 \mu \mathrm{g}$ ), Cefixime (CFM, $5 \mu \mathrm{g}$ ), Amoxicillin (AMX, $30 \mu \mathrm{g}$ ), Piperacillin (PIT, 100/10 $\mu \mathrm{g}$ ), Colistin (CL, 10 $\mu \mathrm{g}$ ), Cefotaxime (CTX, $30 \mu \mathrm{g}$ ) and Cephradine (CE, $30 \mu \mathrm{g}$ ). After placing antibiotic discs properly, the plates were inverted and incubated at $37^{\circ} \mathrm{C}$ for 24 hours. After incubation, the plates were examined and the zone of inhibition was measured in $\mathrm{mm}$.

\section{Statistical analysis}

The data generated in this study were statistically validated using SPSS statistics version 20.0 (IBM, Georgia, USA) and Microsoft Office Excel Professional Plus 2016 (Microsoft Corporation, Redmond, Washington, USA) program packages. The mean values and standard deviations (SD) were determined.

\section{Results and Discussion}

Microbiological quality of the tested water samples collected from ICU and the ability of the bacterial isolates to form biofilms

Nosocomial infections such as bacteremia, tracheobronchitis, sinusitis, urinary tract infections, meningitis, wound infections, peritonitis, ocular infections, and others that are triggered by waterborne bacteria are associated with high morbidity and even [6].
Especially, patients who are admitted to ICU are immunocompromised and are at high risk of these infections [8]. To avoid Nis in ICU, the risk factors need to be detected for undertaking proper preventive actions. Therefore, the present study evaluated the microbiological quality of drinking and tap water samples from ICUs as a potential risk factor of NI.

In the current study, all the water samples collected from different ICUs showed the presence total viable bacteria in an average of $3 \log 10 \mathrm{cfu} / \mathrm{ml}$ (Table 1 ). A significant quantity of specific bacterial species was also recovered from the tested water samples. Bacillus spp. and Pseudomonas spp. were predominantly present in every samples in an average of $2 \log _{10} \mathrm{cfu} / \mathrm{ml}$. Specifically, P. aeruginosa can survive in hospital water for a prolonged period and can cause nosocomial outbreaks [26,27]. E. coli contamination was found in all the water samples except drinking water of ICU-2 (Table 1). Klebsiella spp. were also recovered in water samples collected from ICU-1 and ICU-2. Fecal coliforms were recovered from the tap water sample of ICU-1. Both the water samples from ICU 2 and tap water sample from ICU-1 had contamination with Staphylococcus spp. Vibrio spp. were encountered in the tap water sample of ICU-1 after enrichment (Table 1). Salmonella spp. and Shigella spp. were absent. Previously, Grundmann., et al. [28] found no bacteria in the hospital water samples. In cohort to our study, Anaissie., et al. [6] and Hopman., et al. [2] reported an alarming rate of bacterial contamination in hospital water samples in their studies. Gonsu., et al. [5] and Kirankimar., et al. [8] also found significant numbers of bacteria in the hospital water samples. According to Barrell., et al. [29] and Mansour., et al. [13], the standard limit for E. coli/coliforms and other bacteria is $0 / 100 \mathrm{ml}$ of drinking water in hospital and for tap water, it is $10 / 100 \mathrm{ml}$. Moreover, the CDC recommend using sterile (free from microorganisms water in the ICUs for critical activities [30]. In both contexts, the samples tested in this study portray public health risk upon their uses.

The risk accelerated as some of the bacterial isolates were found to form biofilm on the Congo red media (Table 1). E. coli from drinking water and Pseudomonas spp. from tap water of ICU-1 were able to form biofilm. Biofilm formation by Staphylococcus spp. from drinking water and Pseudomonas spp. from tap water of ICU-2, and E. coli from tap water of ICU-3 was also observed. Biofilm buildup, as well as water stagnation, are among the main causes of poor water quality [6]. Legionella, Pseudomonas, and other waterborne 


\begin{tabular}{|c|c|c|c|c|c|c|c|c|}
\hline \multirow[b]{2}{*}{ Water sample (n) } & \multicolumn{8}{|c|}{ Bacterial load $\left(\log _{10} \mathrm{cfu} / \mathrm{ml}\right)$} \\
\hline & TVB & Bacillus spp. & $\begin{array}{l}\text { Pseudomonas } \\
\text { spp. }\end{array}$ & $\begin{array}{c}\text { Staphylococcus } \\
\text { spp. }\end{array}$ & $\begin{array}{c}\text { Klebsiella } \\
\text { spp. }\end{array}$ & $\begin{array}{c}{ }^{*} \text { Vibrio } \\
\text { spp. }\end{array}$ & E. coli & $\begin{array}{c}\text { Fecal } \\
\text { coliform }\end{array}$ \\
\hline \multicolumn{9}{|l|}{ ICU-1 } \\
\hline Drinking water (5) & $3.5 \pm 0.35$ & $2.9 \pm 0.31$ & $2.6 \pm 0.24$ & $0 \pm 0$ & $2.4 \pm 0.39$ & $0 \pm 0$ & $\# 2.3 \pm 0.18$ & $0 \pm 0$ \\
\hline Tap water (5) & $4.1 \pm 0.41$ & $2.5 \pm 0.35$ & $\# 2.8 \pm 0.33$ & $2.1 \pm 0.21$ & $2.5 \pm 0.26$ & $2.2 \pm 0.19$ & $2.4 \pm 0.14$ & $2.5 \pm 0.13$ \\
\hline \multicolumn{9}{|l|}{ ICU-2 } \\
\hline Drinking water (5) & $3.4 \pm 0.28$ & $3.1 \pm 0.25$ & $3.1 \pm 0.16$ & $\# 2.2 \pm 0.41$ & $2.5 \pm 0.33$ & $0 \pm 0$ & $0 \pm 0$ & $0 \pm 0$ \\
\hline Tap water (5) & $3.4 \pm 0.38$ & $2.8 \pm 0.18$ & $\# 3.4 \pm 0.12$ & $2.7 \pm 0.28$ & $2.6 \pm 0.36$ & $0 \pm 0$ & $2.4 \pm 0.18$ & $0 \pm 0$ \\
\hline \multicolumn{9}{|l|}{ ICU-3 } \\
\hline Drinking water (5) & $3.1 \pm 0.19$ & $2.1 \pm 0.44$ & $2.2 \pm 0.23$ & $0 \pm 0$ & $0 \pm 0$ & $0 \pm 0$ & $2.1 \pm 0.13$ & $0 \pm 0$ \\
\hline Tap water (5) & $3.9 \pm 0.27$ & $2.6 \pm 0.23$ & $2.8 \pm 0.27$ & $0 \pm 0$ & $0 \pm 0$ & $0 \pm 0$ & $\# 2.3 \pm 0.16$ & $0 \pm 0$ \\
\hline
\end{tabular}

Table 1: Bacterial load in the tested ICU water samples.

n- Number of samples; TVB- Total viable bacteria.

The experiments were in triplicates. Mean \pm SD count $\left(\log _{10} \mathrm{cfu} / \mathrm{ml}\right)$ from all samples have been shown here.

\#The isolates were able to produce biofilm on Congo Red media.

*Bacterial load after enrichment (Prior to enrichment, the recovery was nil).

Salmonella spp. and Shigella spp. were absent in all samples.

species have long been known to thrive in biofilms found in water distribution systems and points of use. Biofilms and their pathogenic inhabitants are difficult to eradicate since organisms living in these habitats can be particularly resistant to disinfectants [31]. Overall, the findings of bacteria in significant quantity in every sample tested in this study along with their capacity of forming biofilms in few instances indicative of the poor water treatment and distribution facilities of the hospitals. The water quality was not up to the mark to use in ICUs and might be a major source of nosocomial infections. The hospital should take initiatives to implement effective water treatment facilities including techniques such as boiling, UV light, chemicals like chlorine, electronic purification, and filtration by reverse osmosis.

\section{Recovery of antibiotic resistant bacterial isolates}

The present study investigated the antibiotic susceptibility pattern of the bacteria isolated from the water samples of ICUs as enhanced numbers of multi-drug resistant bacteria in hospitalized patients largely affect their treatments [2]. Increased level of resistance in hospital waterborne isolates was reported against the commonly used antibiotics by many scientists [31-34]. In the present study, all the isolates were found to be resistant against multiple drugs (Table 2-4). In case of isolates from water samples from ICU-1, Cefixime and Amoxicillin resistance was found in every isolates (Table 2). These two are the two most frequently prescribed antibiotics in Bangladesh. Almost all the isolates showed resistance against Cephradine. All the isolates from drinking water was resistant against Piperacillin which showed sensitivity against Bacillus spp. and E. coli in tap water sample. All the isolates were sensitive to Gentamycin and Levofloxacin (Table 2). Few to moderate resistance was found against Trimethoprim/sulfamethoxazole, Colistin, Nalidixic Acid and Cefotaxime.

The isolates from water samples of ICU-2 showed resistance against Cefixime, Amoxicillin and Cephradine (Table 3). On the other hand, all the isolates were sensitive to Levofloxacin and Colistin. The majority of the isolates showed resistance against Piperacillin 


\begin{tabular}{|c|c|c|c|c|c|c|c|c|c|c|}
\hline \multirow{2}{*}{$\begin{array}{c}\text { Isolates from water } \\
\text { samples of ICU-1 }\end{array}$} & \multicolumn{10}{|c|}{ Antibiotics } \\
\hline & GEN & COT & LE & NA & CFM & AMX & PIT & CL & CTX & CE \\
\hline \multicolumn{11}{|l|}{ Drinking water } \\
\hline Bacillus spp. & $\mathrm{S}$ & $\mathrm{R}$ & $\mathrm{S}$ & $\mathrm{R}$ & $\mathrm{R}$ & $\mathrm{R}$ & $\mathrm{R}$ & $\mathrm{S}$ & $\mathrm{R}$ & $\mathrm{R}$ \\
\hline E. coli & S & S & $\mathrm{S}$ & S & $\mathrm{R}$ & $\mathrm{R}$ & $\mathrm{R}$ & $\mathrm{R}$ & $\mathrm{S}$ & $\mathrm{R}$ \\
\hline Klebsiella spp. & S & $\mathrm{R}$ & $\mathrm{S}$ & $\mathrm{R}$ & $\mathrm{R}$ & $\mathrm{R}$ & $\mathrm{R}$ & $\mathrm{S}$ & $\mathrm{R}$ & $\mathrm{R}$ \\
\hline Pseudomonas spp. & $\mathrm{S}$ & $\mathrm{S}$ & $\mathrm{S}$ & $\mathrm{S}$ & $\mathrm{R}$ & $\mathrm{R}$ & $\mathrm{R}$ & $\mathrm{S}$ & $\mathrm{S}$ & $\mathrm{R}$ \\
\hline Vibrio spp. & S & S & $\mathrm{S}$ & $\mathrm{R}$ & $\mathrm{R}$ & $\mathrm{R}$ & $\mathrm{R}$ & $\mathrm{S}$ & $\mathrm{S}$ & $\mathrm{R}$ \\
\hline \multicolumn{11}{|l|}{ Tap water } \\
\hline Bacillus spp. & $\mathrm{S}$ & $\mathrm{S}$ & $\mathrm{S}$ & S & $\mathrm{R}$ & $\mathrm{R}$ & $\mathrm{S}$ & $\mathrm{S}$ & $\mathrm{S}$ & $\mathrm{R}$ \\
\hline Staphylococcus spp. & $\mathrm{S}$ & S & $\mathrm{S}$ & $\mathrm{R}$ & $\mathrm{R}$ & $\mathrm{R}$ & $\mathrm{R}$ & $\mathrm{S}$ & $\mathrm{R}$ & $\mathrm{R}$ \\
\hline Pseudomonas spp. & $\mathrm{S}$ & $S$ & $\mathrm{~S}$ & $\mathrm{R}$ & $\mathrm{R}$ & $\mathrm{R}$ & $\mathrm{R}$ & $\mathrm{S}$ & $\mathrm{R}$ & $\mathrm{R}$ \\
\hline E. coli & $\mathrm{S}$ & S & $\mathrm{S}$ & S & $\mathrm{R}$ & $\mathrm{R}$ & $\mathrm{S}$ & $\mathrm{S}$ & $\mathrm{S}$ & $\mathrm{S}$ \\
\hline
\end{tabular}

Table 2: Antibiotics susceptibility pattern of the isolates from the ICU-1 water samples.

R- Resistant; S- Sensitive.

GEN- Gentamycin (10 $\mu \mathrm{g}$ ); COT- Trimethoprim/sulfamethoxazole (25 $\mu \mathrm{g}$ ); LE- Levofloxacin (5 $\mu \mathrm{g})$; NA- Nalidixic Acid (30 $\mu$ g); CFM- Cefix-

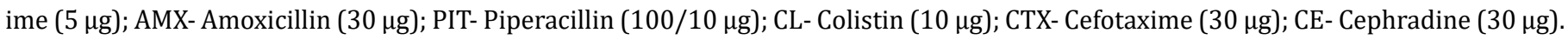

\begin{tabular}{|c|c|c|c|c|c|c|c|c|c|c|}
\hline \multirow{2}{*}{$\begin{array}{l}\text { Isolates from water } \\
\text { samples of ICU-2 }\end{array}$} & \multicolumn{10}{|c|}{ Antibiotics } \\
\hline & GEN & COT & LE & NA & CFM & AMX & PIT & CL & CTX & $\mathrm{CE}$ \\
\hline \multicolumn{11}{|l|}{ Drinking water } \\
\hline Bacillus spp. & $\mathrm{S}$ & $\mathrm{S}$ & S & $\mathrm{S}$ & $\mathrm{R}$ & $\mathrm{R}$ & $\mathrm{R}$ & $\mathrm{S}$ & $S$ & $\mathrm{R}$ \\
\hline Staphylococcus spp. & $S$ & $\mathrm{R}$ & $\mathrm{S}$ & $\mathrm{R}$ & $\mathrm{R}$ & $\mathrm{R}$ & $\mathrm{R}$ & $S$ & $\mathrm{R}$ & $\mathrm{R}$ \\
\hline Klebsiella spp. & $\mathrm{S}$ & $S$ & $\mathrm{~S}$ & $\mathrm{~S}$ & $\mathrm{R}$ & $\mathrm{R}$ & $S$ & $S$ & $\mathrm{R}$ & $\mathrm{R}$ \\
\hline Pseudomonas spp. & $\mathrm{S}$ & $\mathrm{S}$ & $\mathrm{S}$ & $\mathrm{S}$ & $\mathrm{R}$ & $\mathrm{R}$ & $\mathrm{R}$ & $\mathrm{S}$ & $\mathrm{S}$ & $\mathrm{R}$ \\
\hline \multicolumn{11}{|l|}{ Tap water } \\
\hline E. coli & $\mathrm{R}$ & $\mathrm{R}$ & $S$ & $\mathrm{R}$ & $\mathrm{R}$ & $\mathrm{R}$ & $\mathrm{R}$ & $S$ & $\mathrm{R}$ & $\mathrm{R}$ \\
\hline Bacillus spp. & $\mathrm{R}$ & $\mathrm{R}$ & $\mathrm{S}$ & $\mathrm{R}$ & $\mathrm{R}$ & $\mathrm{R}$ & $\mathrm{R}$ & $\mathrm{S}$ & $\mathrm{R}$ & $\mathrm{R}$ \\
\hline Staphylococcus spp. & $\mathrm{S}$ & $\mathrm{R}$ & S & $\mathrm{R}$ & $\mathrm{R}$ & $\mathrm{R}$ & $\mathrm{R}$ & $S$ & $\mathrm{R}$ & $\mathrm{R}$ \\
\hline Pseudomonas spp. & $\mathrm{S}$ & $\mathrm{R}$ & $\mathrm{S}$ & $\mathrm{R}$ & $\mathrm{R}$ & $\mathrm{R}$ & $\mathrm{R}$ & S & $\mathrm{R}$ & $\mathrm{R}$ \\
\hline Klebsiella spp. & $\mathrm{R}$ & $\mathrm{R}$ & $\mathrm{S}$ & $\mathrm{R}$ & $\mathrm{R}$ & $\mathrm{R}$ & $\mathrm{R}$ & S & $\mathrm{R}$ & $\mathrm{R}$ \\
\hline
\end{tabular}

Table 3: Antibiotics susceptibility pattern of the isolates from the ICU-2 water samples.

R- Resistant; S- Sensitive.

GEN- Gentamycin (10 $\mu \mathrm{g})$; COT- Trimethoprim/sulfamethoxazole (25 $\mu \mathrm{g})$; LE- Levofloxacin (5 $\mu \mathrm{g})$; NA- Nalidixic Acid (30 $\mu$ g); CFM- Cefix-

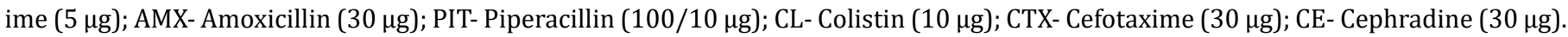




\begin{tabular}{|c|c|c|c|c|c|c|c|c|c|c|}
\hline \multirow{2}{*}{$\begin{array}{c}\text { Isolates from water } \\
\text { samples of ICU-3 }\end{array}$} & \multicolumn{10}{|c|}{ Antibiotics } \\
\hline & GEN & COT & LE & NA & CFM & AMX & PIT & CL & CTX & CE \\
\hline \multicolumn{11}{|l|}{ Drinking water } \\
\hline Bacillus spp. & $S$ & $\mathrm{~S}$ & $\mathrm{~S}$ & $\mathrm{R}$ & $\mathrm{R}$ & $S$ & $S$ & $\mathrm{~S}$ & $S$ & $\mathrm{R}$ \\
\hline Staphylococcus spp. & S & $\mathrm{S}$ & $\mathrm{S}$ & $\mathrm{S}$ & $\mathrm{R}$ & $\mathrm{S}$ & $\mathrm{S}$ & $\mathrm{S}$ & S & $\mathrm{R}$ \\
\hline E. coli & $\mathrm{S}$ & $S$ & $\mathrm{~S}$ & $\mathrm{~S}$ & $\mathrm{R}$ & $\mathrm{R}$ & $\mathrm{R}$ & $\mathrm{S}$ & $S$ & $\mathrm{R}$ \\
\hline Pseudomonas spp. & $\mathrm{S}$ & $S$ & $\mathrm{~S}$ & $\mathrm{R}$ & $\mathrm{R}$ & $S$ & $\mathrm{~S}$ & $\mathrm{~S}$ & $S$ & $\mathrm{R}$ \\
\hline \multicolumn{11}{|l|}{ Tap water } \\
\hline Bacillus spp. & S & $S$ & $\mathrm{~S}$ & $\mathrm{R}$ & $\mathrm{R}$ & $\mathrm{R}$ & $\mathrm{R}$ & $\mathrm{R}$ & S & $\mathrm{R}$ \\
\hline Staphylococcus spp. & $\mathrm{S}$ & $S$ & $\mathrm{~S}$ & $\mathrm{R}$ & $\mathrm{R}$ & $\mathrm{S}$ & $\mathrm{S}$ & $\mathrm{S}$ & $S$ & $\mathrm{R}$ \\
\hline Pseudomonas spp. & $\mathrm{S}$ & $\mathrm{S}$ & $\mathrm{S}$ & $\mathrm{R}$ & $\mathrm{R}$ & $\mathrm{R}$ & $\mathrm{I}$ & $\mathrm{S}$ & $\mathrm{S}$ & $\mathrm{R}$ \\
\hline E. coli & $\mathrm{S}$ & $S$ & $\mathrm{~S}$ & $\mathrm{R}$ & $\mathrm{R}$ & $\mathrm{R}$ & $\mathrm{R}$ & $\mathrm{S}$ & $\mathrm{S}$ & $\mathrm{R}$ \\
\hline
\end{tabular}

Table 4: Antibiotics susceptibility pattern of the isolates from the ICU-3 water samples.

R- Resistant; S- Sensitive.

GEN- Gentamycin (10 $\mu$ g); COT- Trimethoprim/sulfamethoxazole (25 $\mu \mathrm{g}$ ); LE- Levofloxacin (5 $\mu$ g); NA- Nalidixic Acid (30 $\mu$ g); CFM- Cefix-

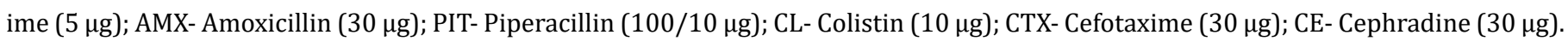

and Cefotaxime. Trimethoprim/sulfamethoxazole resistance was found in all the tap water isolates, while sensitivity was found in isolates from drinking water (Table 3). In cases of isolates from the water samples of ICU-3, Amoxicillin and Cephradine resistance was observed in all the isolates (Table 4). All the isolates exhibited sensitivity against Gentamycin, Trimethoprim/sulfamethoxazole, Levofloxacin and Cefotaxime. Low to moderate rate of resistance was found against Nalidixic Acid, Amoxicillin, Piperacillin and Colistin (Table 4). In the current research, the high rate of drug resistance in bacterial species may be due to the widespread use of antibiotics in hospitals.

\section{Conclusion}

The findings of the present study reveal that the drinking and tap water samples from ICU of different hospitals contained different types of specific bacteria that were multi-drug resistant and a few could form biofilm. Such contaminated water in the ICU area of a hospital may pose a serious threat to patient health as the patients are critically immunocompromised. To ensure that pathogens do not spread by contaminated water, adequate water facilities are therefore an important requisite. Given the greater vulnerability of these patients who are admitted to ICU (usually at the peak of their immunosuppression), hospitals that are dealing with such patients should have higher drinking water quality levels than the community and should take urgent steps to avoid waterborne infections.

\section{Acknowledgements}

We thank Stamford University Bangladesh for proving laboratory facilities, technical and financial support.

\section{Conflict of Interest}

Authors have no potential conflict of interest.

\section{Bibliography}

1. Dasgupta S., et al. "Nosocomial infections in the intensive care unit: Incidence, risk factors, outcome and associated pathogens in a public tertiary teaching hospital of Eastern India”. Indian Journal of Critical Care Medicine 19.1 (2015): 14-20.

2. Hopman J., et al. "Reduced rate of intensive care unit acquired gram-negative bacilli after removal of sinks and introduction of 'water-free' patient care". Antimicrobial Resistance and Infection Control 6 (2017): 59. 
3. Maltezou HC., et al. "Infection control practices in facilities for highly infectious diseases across Europe". Journal of Hospital Infection 81.3 (2012):184-191.

4. Dancer SJ. "Controlling hospital-acquired infection: focus on the role of the environment and new technologies for decontamination". Clinical Microbiology Reviews 27.4 (2014): 665690.

5. Gonsu KH., et al. "Bacteriological assessment of the hospital environment in two referral hospitals in Yaoundé-Cameroon". The Pan African Medical Journal 20 (2015): 224.

6. Anaissie EJ., et al. "The hospital water supply as a source of nosocomial infections". Archives of Internal Medicine 162.13 (2002):1483-1492.

7. Mara D., et al. "Sanitation and health". PLoS Medicine 7.11 (2010): e1000363.

8. Kirankumar Y., et al. "Bacteriological analysis of water samples from different points in a tertiary care hospital". Journal of Clinical and Diagnostic Research 13.19 (2019): DC04-DC09.

9. Ashbolt NJ. "Microbial contamination of drinking water and disease outcomes in developing regions". Toxicology 198 (2004): 229-238.

10. Zamxaka M., et al. "Microbiological and physico-chemical assessment of the quality of domestic water sources in selected rural communities of the Eastern Cape Province, South Africa". Water SA 30 (2004): 333-340.

11. Trautmann M., et al. "Tap water colonization with Pseudomonas aeruginosa in a surgical intensive care unit (ICU) and relation to Pseudomonas infections of ICU patients". Infection Control and Hospital Epidemiology 22 (2001): 2249-2252.

12. Perkins KM., et al. "Investigation of healthcare infection risks from water-related organisms: Summary of CDC consultations, 2014-2017". Infection Control and Hospital Epidemiology 40.6 (2019): 621-626.

13. Mansour 0., et al. "Analyze study of water in emergency departments at general hospitals of the Syrian coast". Research Journal of Pharmacy and Technology 10.1 (2017): 1-6.
14. Nahar A., et al. "Isolation of Acinetobacter species and their antibiotic resistance pattern in an intensive care unit (ICU) of a tertiary care hospital in Dhaka, Bangladesh". Bangladesh Journal of Medical Microbiology 6.1 (2012): 3-6.

15. Islam T., et al. "Bacterial propagation in municipal water and deep tube-well water in kashipur locality of Narayanganj City, Bangladesh". Journal of Water and Environment Technology 18.5 (2020): 327-337.

16. Acharjee M., et al. "Bacterial proliferation in municipal water supplied in Mirpur locality of Dhaka city, Bangladesh". Clean Soil Air Water 42.4 (2014): 434-441.

17. Munshi SK., et al. "Detection of virulence potential of diarrheagenic Escherichia coli isolated from surface water rivers surrounding Dhaka city". Journal of Bangladesh Academy of Sciences 36.1 (2012): 109-121.

18. Ahmed T., et al. "Microbiological study of drinking water: qualitative and quantitative approach". Asian Journal of Microbiology, Biotechnology and Environmental Sciences 15.4 (2013): 23-30.

19. Hossaini F., et al. "Antimicrobial traits of different medicinal plants locally available in Bangladesh". Biomedical and Biotechnology Research Journal 5.1 (2021): 1-6.

20. Hossaini F., et al. "Antimicrobial effects of different extracts of medicinally used green leafy vegetables collected from local market of Dhaka". Food Research 4.3 (2020): 860-865.

21. Akter M., et al. "Microbiological quality assessment of readyto-eat fried chicken and chicken soup samples sold in Dhaka Metropolis, Bangladesh". Sumerianz Journal of Biotechnology 2.7 (2019): 48-54.

22. Akter A., et al. "Occurrence of drug resistant bacteria in household waste samples". Stamford Journal of Microbiology 9.1 (2019): 15-18.

23. Munshi SK., et al. "Influence of multi-species biofilm formed in vitro from different environmental samples on the drugresistance traits of resident bacteria". Bangladesh Journal of Microbiology 35.2 (2018): 108-114. 
24. Kaiser TDL., et al. "Modification of the Congo red agar method to detect biofilm production by Staphylococcus epidermidis". Diagnostic Microbiology and Infectious Disease 75.3 (2013): 235-239.

25. Das NC., et al. "Influence of tannery wastes and the surrounding environment of tannery industries on microbial growth and proliferation". Stamford Journal of Microbiology 7.1 (2017): 14-18.

26. Leitner E., et al. "Contaminated handwashing sinks as the source of a clonal outbreak of KPC-2-producing Klebsiella oxytoca on a hematology ward". Antimicrobial Agents and Chemotherapy 59.1 (2015): 714-716.

27. Guyot A., et al. "Outbreak of Stenotrophomonas maltophilia on an intensive care unit". Journal of Hospital Infection 85.4 (2013): 303-307.

28. Grundmann H., et al. "Pseudomonas aeruginosa in a neonatal intensive care unit: reservoirs and ecology of the nosocomial pathogen". Journal of Infectious Disease 168.4 (1993): 943-947.

29. Barrell R., et al. "Microbiological standards for water and their relationship to health risk". Communicable Disease and Public Health 3 (2000): 8-13.

30. Eckmanns T., et al. "An outbreak of hospital-acquired Pseudomonas aeruginosa infection caused by contaminated bottled water in intensive care units". Clinical Microbiology and Infection 14 (2008): 454-458.

31. Decker BK and Palmore TN. "Hospital water and opportunities for infection prevention". Current Infectious Disease Report 16.10 (2014): 432.

32. Ng C., et al. "Characterization of Metagenomes in urban aquatic compartments reveals high prevalence of clinically relevant antibiotic resistance genes in wastewaters". Frontiers in Microbiology 8 (2017): 2200.

33. Yao Y., et al. "Insights into a novel blaKPC-2-encoding IncP-6 plasmid reveal Carbapenem-resistance circulation in several Enterobacteriaceae species from wastewater and a hospital source in Spain". Frontiers in Microbiology 8 (2017):1143.
34. Vergara-Lopez S., et al. "Wastewater drainage system as an occult reservoir in a protracted clonal outbreak due to metallobeta-lactamase-producing Klebsiella oxytoca". Clinical Microbiology and Infection 19.11 (2013): E490-498.

\section{Volume 4 Issue 7 July 2021}

(C) All rights are reserved by Saurab Kishore Munshi., et al. 